\title{
Review \\ Clinical review: Imaging in ischaemic stroke - implications for acute management
}

\author{
Ramez Reda Moustafa and Jean-Claude Baron
}

Department of Clinical Neurosciences, University of Cambridge, Cambridge CB2 2QQ, UK

Corresponding author: Jean-Claude Baron, jcb54@cam.ac.uk

This article is online at http://ccforum.com/content/11/5/227

(c) 2007 BioMed Central Ltd
Published: 11 September 2007

Critical Care 2007, 11:227 (doi:10.1186/cc5973)

clinical decision-making; and motivating new therapeutic developments in the field. The present review will briefly discuss these roles, focusing on recent advances in imaging that pertain to everyday practice.

Imaging has become a cornerstone of stroke management, tran lating pathophysiological knowledge to everyday decision-making. Plain computed tomography is widely available and remains the standard for initial assessment: the technique rules out haemorrhage, visualizes the occluding thrombus and identifies early tissue hypodensity and swelling, which have different implications for thrombolysis. Based on evidence from positron emission tomography (PET), however, multimodal imaging is increasingly advocated. Computed tomography perfusion and angiography provide information on the occlusion site, on recanalization and on the extent of salvageable tissue. Magnetic resonance-based diffusion-weighted imaging (DWI) has exquisite sensitivity for acute ischaemia, however, and there is increasingly robust evidence that DWI combined with perfusion-weighted magnetic resonance imaging $(\mathrm{PWI})$ and angiography improves functional outcome by selecting appropriate patients for thrombolysis (small DWI lesion but large PWI defect) and by ruling out those who would receive no benefit or might be harmed (very large DWI lesion, no PWI defect), especially beyond the 3-hour time window. Combined DWI-PWI also helps predict malignant oedema formation and therefore helps guide selection for early brain decompression. Finally, DWI-PWI is increasingly used for patient selection in therapeutic trials. Although further methodological developments are awaited, implementing the individual pathophysiologic diagnosis based on multimodal imaging is already refining indications for thrombolysis and offers new opportunities for management of acute stroke patients.

\section{Introduction}

In the present era of thrombolysis, of specialized acute stroke units and of endovascular and neurosurgical interventions, imaging has become a cornerstone of modern stroke management. Imaging of the ischaemic process has taken centre stage in four key areas: shaping the basic concepts of stroke pathophysiology; guiding therapeutic approaches that tackle these concepts; translating this knowledge to everyday

\section{Basic concepts}

Following occlusion of a major intracranial artery, particularly the middle cerebral artery (MCA), a gradient of hypoperfusion emerges in the supplied basal ganglia, white matter and cortical mantle [1]. Regions suffering the most severe hypoperfusion (often in and around the sylvian fissure in proximal occlusion) rapidly progress to irreversible damage, representing the 'ischaemic core'. This tissue exhibits very low cerebral blood flow (CBF), cerebral blood volume (CBV) and metabolic rates of oxygen and glucose [2]. The remaining hypoperfused tissue - with lost autoregulation - is pathophysiologically divided relative to a well-defined perfusion threshold into two compartments; namely, the 'penumbra' and the 'oligaemia'.

In the penumbra, oxygen metabolism is preserved relative to $\mathrm{CBF}$, the oxygen extraction fraction is elevated and often reaches its theoretical maximum of $100 \%$ (severe 'misery perfusion'), and the CBV is normal or elevated. Tissue within the penumbra is functionally impaired and contributes to the clinical deficit, yet is still viable and hence potentially salvageable by effective reperfusion. The extent of the penumbra, however, decreases over time by gradual recruitment into the core, and as such represents a key target for therapeutic intervention, albeit with a progressively shrinking temporal window of opportunity - hence the 'time is brain' rule [3]. This course of events varies from patient to patient, but up to one-third of patients still exhibit large volumes of penumbra 18 hours after stroke onset [4].

$\mathrm{ADC}=$ apparent diffusion coefficient; ASPECTS $=$ Alberta Stroke Programme Early CT Score; CBF $=$ cerebral blood flow; CBV $=$ cerebral blood volume; $\mathrm{CT}=$ computed tomography; $\mathrm{DWI}=$ diffusion-weighted imaging; FLAIR = fluid-attenuated inversion recovery; $\mathrm{MCA}=$ middle cerebral artery; $\mathrm{MR}=$ magnetic resonance; $\mathrm{MRI}=$ magnetic resonance imaging; $\mathrm{MTT}=$ mean transit time; $\mathrm{PET}=$ positron emission tomography; PCT = perfusion computed tomography; $\mathrm{PWI}=$ perfusion-weighted imaging; rt-PA $=$ recombinant tissue plasminogen activator; TTP $=$ time to peak. 


\section{Figure 1}

(a)

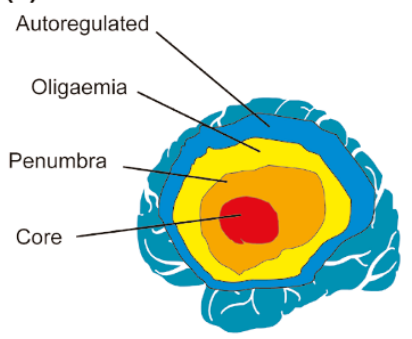

(b)

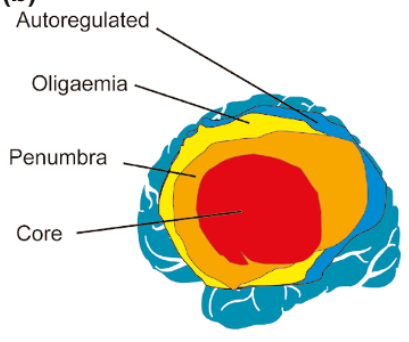

Hypoperfused tissue compartments after acute MCA occlusion and the consequences of decreasing cerebral perfusion pressure. (a) The three hypoperfused tissue compartments (the core, the penumbra and the oligaemia) after acute middle cerebral artery occlusion. A further compartment with normal perfusion but partially exhausted vascular reserve (denoted autoregulated) surrounds the oligaemic compartment (see text). (b) Consequences of decreasing cerebral perfusion pressure, as a result of, for example, a fall in systemic blood pressure or an increase in intracranial pressure from vasogenic oedema, on the four tissue compartments illustrated in (a), showing an enlargement of the core at the expense of the penumbra, and of the latter into the oligaemia and autoregulated compartments, with attending clinical deterioration. The final infarction potentially involves all four compartments entirely.

The oligaemic compartment, on the other hand, suffers a milder degree of hypoperfusion with normal oxygen consumption and with elevated CBV and oxygen extraction fraction, and is not normally at risk of infarction [4]. If the occlusion persists, however, secondary events such as systemic hypotension, intracranial hypertension or hyperglycaemia may topple this delicate balance and force the oligaemia into a penumbral state, and eventually recruitment into the necrotic core. Figure 1 illustrates these concepts.

This understanding of the pathophysiology underlies the urgency of acute stroke management and is the rationale for approaches, established or still experimental, to rescue the penumbra, such as reperfusion therapy, neuroprotection, induced arterial hypertension and oxygen therapy. Besides being instrumental in this development, imaging in the acute setting brings these physiological concepts to the bedside and aims to identify the different tissue compartments amenable to therapy and to define the potential for recovery in the individual patient.

\section{Imaging techniques}

\section{Plain computed tomography}

Despite being surpassed by magnetic resonance imaging (MRI) in versatility and image quality, plain computed tomography (CT) remains the standard tool for initial assessment in most centres because it is widely available and because the large thrombolysis trials were all CT-based [5,6]. Apart from ruling out haemorrhage, early tissue ischaemic changes can be identified by CT within 3 hours of onset in up to $75 \%$ of patients with MCA stroke [7], yet with moderate interobserver agreement depending on experience [8]. These changes comprise: tissue hypodensity, which is associated with severe reductions in CBF and CBV on perfusion imaging [9] and whose extent can predict final infarction [10]; and cortical swelling without hypodensity, which on MRI is associated with increased CBV, moderate hypoperfusion and a normal or near-normal apparent diffusion coefficient (ADC), reflecting salvageable tissue [11].

Early ischaemic changes thus include elements of both the core and the penumbra. Large parenchymal hypodensity also statistically predicts the risk of thrombolysis-associated haemorrhage, hence the widespread notion of withholding this treatment if it exceeds one-third of the MCA territory [6]. The Alberta Stroke Programme Early CT Score (ASPECTS) [7] has better interrater reliability in assessing early ischaemic changes [12], yet this is not independently associated with poor clinical outcome [13]. Since the ASPECTS combines swelling and hypodensity, it may not distinguish irreversibly damaged tissue from viable tissue. A recent study comparing CT with MRI [14] has confirmed that focal brain swelling does not always represent infarcted tissue, supporting the removal of this criterion from the ASPECTS scoring system.

An additional early CT sign in ischaemic stroke is the direct visualization of the thrombus, seen as increased attenuation in the transverse M1 segment (hyperdense MCA sign) or in cross-section within the sylvian fissure (dot sign) [15]. The specificity of these signs is high, but their sensitivity is moderate (30-40\%) [16], probably because CT cannot detect fresh fibrin-poor thrombi [17]. In a general stroke population, the hyperdense MCA sign is associated with poor prognosis and a risk of thrombolysis-associated haemorrhage [18], but its resolution is associated with a favourable outcome. In patients with acute MCA occlusion, however, this sign has no independent prognostic value [19]. Equivalent signs have recently been reported on MRI [20].

Plain CT is also very sensitive to intracranial haemorrhage and subarachnoid haemorrhage. Studies using gradientrecalled echo $\mathrm{T}^{*}$ $\mathrm{MRI}$, however, have shown that intracranial haemorrhage can be equally detected with very high sensitivity even by inexperienced users [21,22], and that fluidattenuated inversion recovery (FLAIR) MRI can also demonstrate subarachnoid haemorrhage equally well [23]. These findings may support the idea of omitting CT as the initial investigation in acute stroke and proceeding directly to MRI (see below).

\section{Computed tomography and magnetic resonance angiography}

In the acute setting, CT or magnetic resonance (MR) angiography can determine the site of occlusion, early recanalization and the presence of abnormalities in the proximal arterial tree such as stenosis, occlusion or dissection, pertaining to 
the cause of the stroke [24]. These data can usefully inform the decision to use intravenous thrombolysis or to proceed to mechanical embolectomy, for example in 'T occlusion' of the carotid termination $[25,26]$. Unlike CT, time-of-flight MR angiography is noninvasive, utilizing the intrinsic properties of moving blood [27]. Although less accurate than contrastenhanced MR angiography, this makes the technique particularly appealing when combined with perfusionweighted imaging $(\mathrm{PWI})$ as it avoids the repeated use of a contrast agent.

Source images from CT angiography can themselves be used to detect areas of very low CBV, which are comparable with MRI diffusion-weighted imaging (DWI) lesions [24,28] and are predictive of subsequent infarction within 6 hours [29]. The added value is attractive, yet the technique still needs to be fully validated.

DWI remains by far the most sensitive method of detecting acute ischaemia $[30,31]$ and can be positive a few minutes from onset [32], allowing accurate localization and subtyping of stroke. The DWI signal reflects restriction of the random motion of water in tissue and the decline of its ADC although the exact biological correlates are not completely understood, this probably involves energy failure and subsequent cytotoxic oedema [33,34]. In combination with perfusion imaging, DWI can also be used, albeit cautiously, to define the ischaemic core and the penumbra [35] (see below).

\section{Multimodal stroke imaging}

Largely based on seminal positron emission tomography (PET) observations $[3,4,36]$, most authorities nowadays consider that the heterogeneity and complexity of acute ischaemic stroke necessitates a multimodal approach to imaging that provides not only structural but also functional and haemodynamic information to aid the decision-making process [37]. For CT this approach currently includes plain $\mathrm{CT}, \mathrm{CT}$ angiography and perfusion computed tomography (PCT) $[28,38]$, while in MRI the approach includes a combination of conventional sequences (such as T1W, T2W and fluid-attenuated inversion recovery) and $\mathrm{T} 2{ }^{*} \mathrm{~W}$, time-offlight MR angiography, DWI and PWI [39].

\section{Perfusion computed tomography}

PCT images are acquired in the cine mode after intravenous injection of an iodinated contrast agent, generating maps of $\mathrm{CBF}, \mathrm{CBV}$ as well as mean transit time (MTT) and time to peak (TTP) [40]. The maps are reproducible, especially when relative perfusion parameters are used [41], and reportedly have $>90 \%$ sensitivity and specificity for detecting large hemispheric stroke [42]. Anatomical coverage, however, is typically restricted to $20 \mathrm{~mm}$ (two to four slices), reducing sensitivity to stroke not caused by proximal major artery occlusion [43].

Recent studies on PCT in acute stroke demonstrated that tissue with $\mathrm{CBV}<2 \mathrm{ml} / 100 \mathrm{~g}$ represents the core, while a relative MTT above $145 \%$ of the normal hemisphere best outlines all at-risk tissue [44]. The penumbra can thus be estimated as the tissue existing between those two thresholds. Using this methodology, PCT parameters correlate very well with MR DWI-PWI and are a good predictor of the final infarct volume and clinical recovery $[38,41,45,46]$. PCT is also potentially useful in decisionmaking when the time of onset is unknown, such as with awakening stroke [47]. In combination with CT angiography, PCT has comparable utility with that of MR in selecting patients for thrombolysis [38].

\section{Magnetic resonance diffusion-perfusion imaging}

The commonly used dynamic susceptibility-weighted contrast PWI technique is similar in principle to PCT, and measures changes in the magnetic field induced by passage of gadolinium-based contrast in cerebral tissue - but with lesser accuracy, particularly for CBF. Arterial spin labelling PWI is a newer technique that avoids the use of a contrast agent through magnetically labelling the arterial blood entering the skull and then tracking its motion through the tissue [48]. The latter technique, however, is less widely available and still requires further validation in stroke.

Among the generated MRI perfusion maps, TTP and MTT are preferred for identifying hypoperfused tissue because they correlate best with tissue fate $[49,50]$. Comparison of the perfusion deficit depicted on these maps with the DWI lesion (assumed to denote the core) yields either a mismatch pattern $(\mathrm{PWI}>\mathrm{DWI})$, a matched lesion pattern $(\mathrm{PWI}=\mathrm{DWI})$ or a reperfusion pattern (DWI $>\mathrm{PWI})$. The mismatch pattern is taken to indicate the existence of salvageable at-risk tissue and is found in about $70 \%$ of all patients with anteriorcirculation stroke within 6 hours of onset [51]. The pattern's presence is strongly associated with proximal MCA occlusion [51] and its resolution on reperfusion is associated with neurological recovery [52-54]. Moreover, successful reperfusion prevents further expansion of the DWI lesion into the area of mismatch [55].

The DWI-PWI mismatch can be used to select patients who are most likely to benefit from thrombolytic therapy [56], and the mismatch is incorporated into several ongoing thrombolysis trials (see below). It has also been used to show how variables such as hyperglycaemia [57], haematocrit [58] and age [59] influence outcome through altering the fate of the penumbra. DWI has also shown utility in providing a physiologic endpoint for new therapies such as normobaric high-flow oxygen [60].

The clinical implications of a matched DWI-PWI pattern are less clear. In the presence of a large DWI lesion and proximal MCA occlusion, this pattern appears to accurately predict the development of a malignant MCA syndrome $[61,62]$. For other scenarios where a matched pattern is found, the evidence is lacking with regard to outcome and with regard 
to whether there is any benefit from instituting thrombolysis or another specific therapy. The third pattern of normal (or increased) perfusion with a variable size DWI lesion indicates recanalization [63], and effectively does not appear to benefit from thrombolysis (see below).

A number of uncertainties have recently arisen regarding the pathophysiologic accuracy of the DWI-PWI mismatch concept. Studies in animals and in humans have documented the reversibility of DWI lesions and normalization of the ADC, thus arguing against equivalence of the DWI lesion to the 'core' [64,65]. Predictors of such normalization are thrombolytic therapy and recanalization, particularly within the 3-hour time window [66]. This suggests that the DWI lesion may include penumbral tissue, as echoed recently using PET $[67,68]$. Corresponding uncertainties also exist regarding $\mathrm{PWI}$, particularly in the selection of parameters for defining the tissue at risk and in the choice of arterial input function $[49,69]$. The DWI-PWI mismatch may thus overestimate the penumbra by including oligaemic tissue or even normally perfused but autoregulated tissue that is not at risk [70]. These questions become particularly relevant when defining the management of matched DWI-PWI lesions, since response to recanalization depends on whether or not there still is penumbral tissue. Nevertheless, the DWI-PWI concept remains a clinically and experimentally useful tool provided these shortcomings are recognized.

\section{Implications of imaging for thrombolysis The 3-hour window}

Patients treated with intravenous thrombolysis within the first 3 hours after stroke are at least 30\% more likely to have little or no disability at 3 months (number needed to treat $=8$ ) $[5,71]$. This is essentially based on selecting patients who have stroke symptoms that are not rapidly resolving or minor (NIH stroke scale <3) with the absence of haemorrhage on plain CT. Nonetheless, despite the use of clinical exclusion criteria [72], the treatment carries a risk of around $6-7 \%$ of thrombolysis-associated symptomatic haemorrhage; therefore, the emerging role of imaging in this acute setting, beyond exclusion of intracranial haemorrhage and subarachnoid haemorrhage, is to identify and exclude that subgroup of patients who are unlikely to benefit and may be harmed by recombinant tissue plasminogen activator (rt-PA), in turn reducing the number needed to treat. As already mentioned, early hypodensity on plain CT >1/3 MCA territory is associated with thrombolysis-associated haemorrhage. Nonetheless, this fact is still debated since analysis of the 0-3 hour group in the NINDS cohort does not support this exclusion on the basis of the extent of early ischaemic changes alone (that is, including swelling) [73].

Similarly, MR-based studies show that severely reduced $\mathrm{ADC}, \mathrm{CBF}$ and $\mathrm{CBV}$ are associated with subsequent haemorrhagic transformation within the infarction [74,75]. These studies, however, do not distinguish symptomatic and asymptomatic grades of haemorrhagic transformation, and thus their relevance to clinical outcome is unclear. Another proposed MRI marker of haemorrhagic transformation is delayed gadolinium enhancement of cerebrospinal fluid space on FLAIR [76]. This marker appears only after reperfusion has been achieved and thus its clinical usefulness is uncertain. Thomalla and colleagues [77] make the distinction between haemorrhagic transformation and parenchymal haemorrhage, arguing that the former is a clinically irrelevant epiphenomenon whereas the latter is a direct effect of rt-PA therapy and deserves further investigation. Finally, T2* MRI can identify microbleeds, which may also arguably pose a risk of parenchymal haemorrhage after thrombolysis, yet the evidence for or against this view is still scarce $[78,79]$.

The constraint of the 3-hour window makes it necessary that imaging is performed in as short a time as possible. Because CT provides relatively limited information in early stroke, multimodal MRI is increasingly being advocated as the imaging investigation of choice [80]. The main concern, however, is the possible delay in treatment - up to 20 minutes in experienced centres [81] - but this may be balanced by the gain in diagnostic accuracy. Furthermore, shorter door-toneedle times can probably be achieved through omitting $\mathrm{CT}$, increasing the familiarity of staff with MRI [82] and tailoring MRI protocols to suit hyperacute stroke patients [39]. Recent data thus indeed suggest that MR-based protocols are of clinical benefit even within the 3-hour window (see below).

\section{Expanding the time window for thrombolysis}

For several reasons, including poor public knowledge about stroke, ineffective delivery of patients to capable centres and lack of preparedness in many community hospitals, only about $20 \%$ of stroke patients arrive at emergency departments within the 3-hour window and only 3-8\% of eligible patients currently receive rt-PA therapy, except in a few regional referral centres [83]. Being able to extend this time window beyond 3 hours will therefore be extremely important. A recent meta-analysis of several rt-PA studies has suggested a potential for a favourable outcome if treatment is given beyond 3 hours [84], and this motivates ongoing thrombolysis trials such as IST3 and ECASS3. Indeed, the pathophysiological model outlined earlier suggests that reperfusion can be beneficial beyond 3 hours through salvage of the penumbra in appropriate patients. Efforts are thus currently directed at adopting acute MR to select suitable patients beyond the 3-hour window.

The Diffusion and Perfusion Imaging Evaluation for Understanding Stroke Evolution (DEFUSE) study used MRI to evaluate treatment with alteplase 3-6 hours from stroke onset, and demonstrated a better clinical response among patients with small DWI and the presence of mismatch on MR than in other subgroups, including the 'matched' DWI-PWI and the small DWI and PWI lesion subgroups 
[85]. The ongoing EPITHET trial [86] further addresses this question by randomizing patients to alteplase or placebo 3-6 hours after stroke onset regardless of the baseline MRI findings, testing the hypothesis that in retrospective analysis patients with mismatch will benefit more than those without.

Studies comparing MRI-based alteplase treatment within 3-6 hours with conventional CT-based treatment within 3 hours have demonstrated similar recanalization rates and functional outcomes [87,88]. Furthermore, MRI-based treatment in the timeframe of 0-6 hours also shows similar or superior safety and efficacy to CT-based treatment within 3 hours, when compared directly [89] or with data from a meta-analysis [90]. Preliminary findings from pooling of results of 1,210 patients confirm and amplify these conclusions [91].

MR-based selection has also been used in two studies testing the new thrombolytic agent desmoteplase. In the Desmoteplase in Acute Ischemic Stroke trial [92], the presence of a MR DWI-PWI mismatch of $20 \%$ or higher was used to select patients for thrombolysis in the window of 3-9 hours. A more favourable clinical outcome was demonstrated in patients who experienced reperfusion than in those who did not (52.5\% versus $24.6 \%$ ), and the treatment effect was independent of the duration from onset to treatment. Similar criteria were also used in the follow-up dose-finding study [93], with good clinical outcome. Results of the Desmoteplase in Acute Ischemic Stroke II study are still awaited. The mismatch concept is also being employed for selecting suitable candidates in ongoing trials of mechanical clot retrieval, such as MERCl.

Finally, MRI is also being employed for selecting suitable candidates in trials of mechanical clot retrieval in posterior circulation stroke [94] where CT is often unhelpful and the evidence is much more limited on the use of thrombolysis.

\section{Implications of imaging for other specific therapies \\ Neuroprotection}

When tested in humans, neuroprotectant agents designed to delay or prevent the demise of at-risk tissue and thus extend the therapeutic time window have consistently failed to produce the effects observed in animal studies. This failure may be attributed in part to the very limited use of physiologic imaging in such trials [95], in addition to potential flaws in trial design, inadequate preclinical data or even the choice of ineffective compounds.

Despite earlier failures, interest has recently been revived in normobaric oxygen therapy in acute stroke. In a pilot study [60], the MRI DWI-PWI mismatch was used to select acute stroke patients ( $<12$ hours from onset) to receive either $100 \%$ oxygen or room air for 8 hours via a face mask. Oxygen-treated patients improved clinically during therapy and at 24 hours, and smaller MR diffusion lesions were seen in this group than in control subjects at early time points. Moreover, oxygen therapy was associated with an increase in relative CBF and CBV within the perfusion (MTT) abnormality, consistent with earlier observations of a vasodilatory response to hyperoxia in ischaemic brain tissue rather than the vasoconstriction induced in normal brain tissue [96]. Larger trials using a similar methodology may eventually establish the usefulness of this simple and widely available approach to neuroprotection.

\section{Surgical brain decompression}

Space-occupying malignant MCA infarctions carry a very poor prognosis under standard therapy, with a case-fatality rate approaching $80 \%$. Decompressive surgery, in the form of wide hemicraniectomy and duraplasty, performed as early as possible (within 48 hours of stroke onset), has been shown in pooled randomized trials to not only significantly reduce mortality by an absolute $50 \%$ but also to improve functional outcome in the survivors, although less impressively [97]. Early decompression probably works not only by preventing life-threatening herniation and subsequent brainstem compression, but also by reducing the detrimental effects of raised intracranial pressure on tissue perfusion pressure, which can precipitate the penumbra, the oligaemia and even perhaps the simply autoregulated tissue into irreversible damage (see Figure 1).

Predicting the development of malignant MCA infarctions as early as possible, particularly from imaging parameters, is thus important to allow surgery to be undertaken in time. Imaging-based predictors such as occlusion of the proximal MCA, carotid T occlusion, involvement of both the superficial and deep MCA territories, an inadequate circle of Willis, and involvement of other vascular territories have modest but useful value $[62,98]$. DWI-PWI MR, however, appears of considerable potential. In one study, a DWI lesion volume above $145 \mathrm{ml}$ within 14 hours of onset was reported to predict this fate with 100\% sensitivity and 94\% specificity [62]. In another study, a smaller ADC lesion volume (82 $\mathrm{ml})$ was advocated if imaging was performed within 6 hours [61]. Furthermore, a ratio of the time to peak to ADC lesion volume $<2.4 \mathrm{and} /$ or an $\mathrm{ADC}$ value within the core $<300 \mathrm{~mm}^{2} / \mathrm{s}$ were also proposed as predictors of malignant MCA infarctions in the same study. In the DEFUSE study [85], a DWI or PWI lesion volume $>100 \mathrm{ml}$ also accurately predicted malignant MCA infarctions. There is also some evidence that other factors such as blood-brain barrier breakdown may be instrumental in the development of malignant infarction [99].

\section{Hypothermia}

Induction of moderate hypothermia (around $33^{\circ} \mathrm{C}$ ) has also been considered in the treatment of malignant MCA infarctions, and some small open studies showed a beneficial effect on clinical outcome $[100,101]$, although with attendant risks of pneumonia and a rebound increase in intracranial pressure on rewarming. The current trend in ongoing trials is 
to go for less dramatic hypothermia (around $35^{\circ} \mathrm{C}$ ), and use intravenous infusion of cooling fluid, which seems less problematic. The Cooling for Acute Ischaemic Brain Damage study used MRI to show a decrease of infarct growth with hypothermia and pointed to its possible effectiveness, yet the small number of patients precluded statistically significant results [102]. Interestingly, marked resolution of the DWI lesion has recently been anecdotally reported after hypothermic treatment [103], thus challenging the inevitable grim outlook of malignant MCA infarctions and suggesting that imaging can be used to select potential responders to such treatment and to monitor treatment effects.

\section{Implications of imaging for general management}

Demonstration of a high oxygen extraction fraction or DWI-PWI mismatch in the setting of acute stroke implies that autoregulation of CBF is impaired in the affected territory. Any lowering of the systemic arterial pressure is therefore likely to further reduce the cerebral perfusion pressure and in turn the CBF in the affected tissue, which can be harmful not only for the penumbra - which may precipitate into necrosis - but also for the oligaemia, which may become penumbral (Figure 1). Accordingly, reductions in systemic arterial pressure in acute ischaemic stroke have frequently been associated with worse outcome [104]. This issue is especially important in view of the frequent occurrence of reactive hypertension in this setting, and is reflected in recommendations for management of blood pressure in acute stroke [71]. Conversely, observing hyperperfusion, particularly if early oedema is demonstrated by CT or MRI, may provide a rationale for treating arterial hypertension since some experimental studies suggest that hyperperfusion in necrotic tissue may promote the development of malignant brain swelling.

\section{Conclusions}

Physiologic imaging in the acute stroke setting allows the clinician to visualize each patient's pathophysiological situation before aggressive therapy is considered [36]. Based on the evidence reviewed above, three main patterns of changes, each with different management implications, can be encountered. If an early extensive core is documented, outcome is invariably poor with considerable risk of malignant MCA infarction, and surgical brain decompression should be considered. Secondly, when early recanalization (without an already extensive core) is documented, spontaneous outcome is invariably good so no aggressive therapy should be considered. Finally, if substantial penumbra (again without extensive core) is documented, management should aim at saving as much penumbra as possible - this pattern includes the best candidates for thrombolysis, although the risk of haemorrhagic transformation should be balanced with the expected benefit. This practical framework is based on current evidence but remains to be formally supported by randomized prospective trials.
This article is part of a review series on Stroke, edited by David Menon.

Other articles in the series can be found online at http://ccforum.com/articles/ theme-series.asp?series=CC_Stroke

Imaging has become an integral part of acute stroke care and the future holds more promise. Considerable evidence is already accumulating that multimodal CT or MRI, as compared with plain CT, provides information that is both useful in clinical trials and in the individual patient, even within the current 3-hour window. In the future, practical implementation of PCT with whole-brain coverage, estimation of CBF by noncontrast arterial spin labelling [48] and of oxygen extraction fraction based on the principles of blood-oxygenlevel-dependent (BOLD) imaging [105], and, possibly, MRbased $\mathrm{pH}$ imaging [106] may add more dimensions to imaging of ischaemic stroke. Future advances in physiologic imaging, such as a readily available means of imaging selective neuronal loss, translating the knowledge from PET and single-photon emission CT studies [107,108], would also further refine our understanding of acute stroke pathophysiology and treatment.

\section{Competing interests}

The authors declare that they have no competing interests.

\section{References}

1. Astrup J, Siesjo BK, Symon L: Thresholds in cerebral ischemia the ischemic penumbra. Stroke 1981, 12:723-725.

2. Marchal G, Benali K, Iglesias S, Viader F, Derlon JM, Baron JC: Voxel-based mapping of irreversible ischaemic damage with PET in acute stroke. Brain 1999, 122(Pt 12):2387-2400.

3. Baron JC, von Kummer R, del Zoppo GJ: Treatment of acute ischemic stroke. Challenging the concept of a rigid and universal time window. Stroke 1995, 26:2219-2221.

4. Baron JC: Mapping the ischaemic penumbra with PET: implications for acute stroke treatment. Cerebrovasc Dis 1999, 9: 193-201.

5. Tissue plasminogen activator for acute ischemic stroke. The National Institute of Neurological Disorders and Stroke rt-PA Stroke Study Group. N Engl J Med 1995, 333:1581-1587.

6. Hacke W, Kaste M, Fieschi C, von Kummer R, Davalos A, Meier D, Larrue V, Bluhmki E, Davis S, Donnan G, et al:: Randomised double-blind placebo-controlled trial of thrombolytic therapy with intravenous alteplase in acute ischaemic stroke (ECASS II). Second European-Australasian Acute Stroke Study Investigators. Lancet 1998, 352:1245-1251.

7. Barber PA, Demchuk AM, Zhang J, Buchan AM: Validity and reliability of a quantitative computed tomography score in predicting outcome of hyperacute stroke before thrombolytic therapy. ASPECTS Study Group. Alberta Stroke Programme Early CT Score. Lancet 2000, 355:1670-1674.

8. Grotta JC, Chiu D, Lu M, Patel S, Levine SR, Tilley BC, Brott TG, Haley EC, Jr, Lyden PD, Kothari R, et al.: Agreement and variability in the interpretation of early CT changes in stroke patients qualifying for intravenous rtPA therapy. Stroke 1999, 30:1528-1533.

9. Kucinski T, Majumder A, Knab R, Naumann D, Fiehler J, Vaterlein $\mathrm{O}$, Eckert $\mathrm{B}$, Rother J, Zeumer $\mathrm{H}$ : Cerebral perfusion impairment correlates with the decrease of CT density in acute ischaemic stroke. Neuroradiology 2004, 46:716-722. 
10. von Kummer R, Bourquain H, Bastianello S, Bozzao L, Manelfe C, Meier D, Hacke W: Early prediction of irreversible brain damage after ischemic stroke at CT. Radiology 2001, 219:95100.

11. Na DG, Kim EY, Ryoo JW, Lee KH, Roh HG, Kim SS, Song IC, Chang $\mathrm{KH}$ : CT sign of brain swelling without concomitant parenchymal hypoattenuation: comparison with diffusion- and perfusion-weighted MR imaging. Radiology 2005, 235:992998.

12. Coutts SB, Demchuk AM, Barber PA, Hu WY, Simon JE, Buchan $A M$, Hill MD: Interobserver variation of ASPECTS in real time. Stroke 2004, 35:e103-e105.

13. Patel SC, Levine SR, Tilley BC, Grotta JC, Lu M, Frankel M, Haley EC, Jr, Brott TG, Broderick JP, Horowitz S, et al.: Lack of clinical significance of early ischemic changes on computed tomography in acute stroke. JAMA 2001, 286:2830-2838.

14. Butcher KS, Lee SB, Parsons MW, Allport L, Fink J, Tress B, Donnan G, Davis SM: Differential prognosis of isolated cortical swelling and hypoattenuation on CT in acute stroke. Stroke 2007, 38:941-947.

15. Leary MC, Kidwell CS, Villablanca JP, Starkman S, Jahan R, Duckwiler GR, Gobin YP, Sykes S, Gough KJ, Ferguson K, et al.: Validation of computed tomographic middle cerebral artery 'dot' sign: an angiographic correlation study. Stroke 2003, 34:26362640.

16. Barber PA, Demchuk AM, Hill MD, Pexman JH, Hudon ME, Frayne $\mathrm{R}$, Buchan AM: The probability of middle cerebral artery MRA flow signal abnormality with quantified $C T$ ischaemic change: targets for future therapeutic studies. J Neurol Neurosurg Psychiatry 2004, 75:1426-1430.

17. Kirchhof K, Welzel T, Mecke C, Zoubaa S, Sartor K: Differentiation of white, mixed, and red thrombi: value of CT in estimation of the prognosis of thrombolysis phantom study. Radiology 2003, 228:126-130.

18. Qureshi Al, Ezzeddine MA, Nasar A, Suri MF, Kirmani JF, Janjua N, Divani AA: Is IV tissue plasminogen activator beneficial in patients with hyperdense artery sign? Neurology 2006, 66: 1171-1174.

19. von Kummer R, Meyding-Lamade U, Forsting $M$, Rosin L, Rieke $K$, Hacke W, Sartor K: Sensitivity and prognostic value of early CT in occlusion of the middle cerebral artery trunk. Am J Neuroradiol 1994, 15:9-15; discussion 16-18.

20. Kim HS, Lee DH, Choi CG, Kim SJ, Suh DC: Progression of middle cerebral artery susceptibility sign on $\mathrm{T}^{*}$-weighted images: its effect on recanalization and clinical outcome after thrombolysis. Am J Roentgenol 2006, 187:W650-W657.

21. Fiebach JB, Schellinger PD, Gass A, Kucinski T, Siebler M, Villringer A, Olkers $P$, Hirsch JG, Heiland S, Wilde P, et al.: Stroke magnetic resonance imaging is accurate in hyperacute intracerebral hemorrhage: a multicenter study on the validity of stroke imaging. Stroke 2004, 35:502-506.

22. Kidwell CS, Chalela JA, Saver JL, Starkman S, Hill MD, Demchuk AM, Butman JA, Patronas N, Alger JR, Latour LL, et al.: Comparison of MRI and CT for detection of acute intracerebral hemorrhage. JAMA 2004, 292:1823-1830.

23. Noguchi $K$, Ogawa $T$, Inugami $A$, Toyoshima $H$, Sugawara $S$, Hatazawa J, Fujita H, Shimosegawa E, Kanno I, Okudera T, et al.: Acute subarachnoid hemorrhage: MR imaging with fluidattenuated inversion recovery pulse sequences. Radiology 1995, 196:773-777.

24. Ezzeddine MA, Lev MH, McDonald CT, Rordorf G, Oliveira-Filho J, Aksoy FG, Farkas J, Segal AZ, Schwamm LH, Gonzalez RG, et al:: CT angiography with whole brain perfused blood volume imaging: added clinical value in the assessment of acute stroke. Stroke 2002, 33:959-966.

25. Wunderlich MT, Stolz E, Seidel G, Postert T, Gahn G, Sliwka U, Goertler M: Conservative medical treatment and intravenous thrombolysis in acute stroke from carotid T occlusion. Cerebrovasc Dis 2005, 20:355-361.

26. Jansen $O$, von Kummer $R$, Forsting $M$, Hacke W, Sartor $K$ : Thrombolytic therapy in acute occlusion of the intracranial internal carotid artery bifurcation. Am J Neuroradiol 1995, 16: 1977-1986.

27. Graves MJ: Magnetic resonance angiography. $\mathrm{Br} J$ Radiol 1997, 70:6-28.

28. Schramm P, Schellinger PD, Klotz E, Kallenberg K, Fiebach JB, Kulkens S, Heiland S, Knauth M, Sartor K: Comparison of perfu- sion computed tomography and computed tomography angiography source images with perfusion-weighted imaging and diffusion-weighted imaging in patients with acute stroke of less than 6 hours' duration. Stroke 2004, 35:1652-1658.

29. Hunter GJ, Hamberg LM, Ponzo JA, Huang-Hellinger FR, Morris PP, Rabinov J, Farkas J, Lev MH, Schaefer PW, Ogilvy CS, et al.: Assessment of cerebral perfusion and arterial anatomy in hyperacute stroke with three-dimensional functional CT: early clinical results. Am J Neuroradiol 1998, 19:29-37.

30. Fiebach JB, Schellinger PD, Jansen O, Meyer M, Wilde $P$, Bender J, Schramm P, Juttler E, Oehler J, Hartmann M, et al.: CT and diffusion-weighted MR imaging in randomized order: diffusionweighted imaging results in higher accuracy and lower interrater variability in the diagnosis of hyperacute ischemic stroke. Stroke 2002, 33:2206-2210.

31. Lovblad KO, Laubach HJ, Baird AE, Curtin F, Schlaug G, Edelman $\mathrm{RR}$, Warach S: Clinical experience with diffusion-weighted MR in patients with acute stroke. Am J Neuroradiol 1998, 19:10611066.

32. Hjort N, Christensen S, Solling C, Ashkanian M, Wu O, Rohl L, Gyldensted C, Andersen G, Ostergaard L: Ischemic injury detected by diffusion imaging 11 minutes after stroke. Ann Neurol 2005, 58:462-465.

33. Busza $A L$, Allen $K L$, King $M D$, van Bruggen $N$, Williams $S R$, Gadian DG: Diffusion-weighted imaging studies of cerebral ischemia in gerbils. Potential relevance to energy failure. Stroke 1992, 23:1602-1612.

34. Nicoli F, Lefur Y, Denis B, Ranjeva JP, Confort-Gouny S, Cozzone $\mathrm{PJ}$ : Metabolic counterpart of decreased apparent diffusion coefficient during hyperacute ischemic stroke: a brain proton magnetic resonance spectroscopic imaging study. Stroke 2003, 34:e82-e87.

35. Schlaug G, Benfield A, Baird AE, Siewert B, Lovblad KO, Parker RA, Edelman RR, Warach $S$ : The ischemic penumbra: operationally defined by diffusion and perfusion MRI. Neurology 1999, 53:1528-1537.

36. Marchal G, Serrati C, Rioux P, Petit-Taboue MC, Viader F, de la Sayette V, Le Doze F, Lochon P, Derlon JM, Orgogozo JM, et al.: PET imaging of cerebral perfusion and oxygen consumption in acute ischaemic stroke: relation to outcome. Lancet 1993, 341:925-927.

37. Muir KW, Buchan A, von Kummer R, Rother J, Baron JC: Imaging of acute stroke. Lancet Neuro/ 2006, 5:755-768.

38. Wintermark M, Meuli R, Browaeys $P$, Reichhart M, Bogousslavsky J, Schnyder P, Michel P: Comparison of CT perfusion and angiography and MRI in selecting stroke patients for acute treatment. Neurology 2007, 68:694-697.

39. U-King-Im JM, Trivedi RA, Graves MJ, Harkness K, Eales H, Joubert I, Koo B, Antoun N, Warburton EA, Gillard JH, et al:: Utility of an ultrafast magnetic resonance imaging protocol in recent and semi-recent strokes. J Neurol Neurosurg Psychiatry 2005, 76:1002-1005

40. Wintermark M, Sesay M, Barbier E, Borbely K, Dillon WP, Eastwood JD, Glenn TC, Grandin CB, Pedraza S, Soustiel JF, et al.: Comparative overview of brain perfusion imaging techniques. Stroke 2005, 36:e83-e99.

41. Muir KW, Halbert HM, Baird TA, McCormick M, Teasdale E: Visual evaluation of perfusion computed tomography in acute stroke accurately estimates infarct volume and tissue viability. J Neurol Neurosurg Psychiatry 2006, 77:334-339.

42. Wintermark M, Fischbein NJ, Smith WS, Ko NU, Quist M, Dillon WP: Accuracy of dynamic perfusion CT with deconvolution in detecting acute hemispheric stroke. Am J Neuroradiol 2005, 26:104-112.

43. Maruya J, Yamamoto K, Ozawa T, Nakajima T, Sorimachi T, Kawasaki T, Tanaka R: Simultaneous multi-section perfusion CT and CT angiography for the assessment of acute ischemic stroke. Acta Neurochir (Wien) 2005, 147:383-391; discussion 391-382.

44. Wintermark $M$, Flanders $A E$, Velthuis $B$, Meuli $R$, van Leeuwen $M$, Goldsher D, Pineda C, Serena J, van der Schaaf I, Waaijer A, et al: Perfusion-CT assessment of infarct core and penumbra: receiver operating characteristic curve analysis in 130 patients suspected of acute hemispheric stroke. Stroke 2006, 37:979-985.

45. Wintermark M, Reichhart M, Thiran JP, Maeder P, Chalaron M, Schnyder P, Bogousslavsky J, Meuli R: Prognostic accuracy of 
cerebral blood flow measurement by perfusion computed tomography, at the time of emergency room admission, in acute stroke patients. Ann Neurol 2002, 51:417-432.

46. Eastwood JD, Lev MH, Wintermark M, Fitzek C, Barboriak DP, Delong DM, Lee TY, Azhari T, Herzau M, Chilukuri VR, et al:: Correlation of early dynamic $C T$ perfusion imaging with wholebrain MR diffusion and perfusion imaging in acute hemispheric stroke. Am J Neuroradio/ 2003, 24:1869-1875.

47. Hellier KD, Hampton JL, Guadagno JV, Higgins NP, Antoun N, Day DJ, Gillard JH, Warburton EA, Baron JC: Perfusion CT helps decision making for thrombolysis when there is no clear time of onset. J Neurol Neurosurg Psychiatry 2006, 77:417-419.

48. Petersen ET, Zimine I, Ho YC, Golay X: Non-invasive measurement of perfusion: a critical review of arterial spin labelling techniques. Br J Radiol 2006, 79:688-701.

49. Sobesky J, Zaro Weber O, Lehnhardt FG, Hesselmann V, Thiel A, Dohmen C, Jacobs A, Neveling M, Heiss WD: Which time-topeak threshold best identifies penumbral flow? A comparison of perfusion-weighted magnetic resonance imaging and positron emission tomography in acute ischemic stroke. Stroke 2004, 35:2843-2847.

50. Grandin CB, Duprez TP, Smith AM, Oppenheim C, Peeters A, Robert AR, Cosnard G: Which MR-derived perfusion parameters are the best predictors of infarct growth in hyperacute stroke? Comparative study between relative and quantitative measurements. Radiology 2002, 223:361-370.

51. Barber PA, Davis SM, Darby DG, Desmond PM, Gerraty RP, Yang Q, Jolley D, Donnan GA, Tress BM: Absent middle cerebral artery flow predicts the presence and evolution of the ischemic penumbra. Neurology 1999, 52:1125-1132.

52. Staroselskaya IA, Chaves C, Silver B, Linfante I, Edelman RR, Caplan L, Warach S, Baird AE: Relationship between magnetic resonance arterial patency and perfusion-diffusion mismatch in acute ischemic stroke and its potential clinical use. Arch Neurol 2001, 58:1069-1074.

53. Singer OC, Du Mesnil De Rochemont R, Foerch C, Stengel A, Sitzer M, Lanfermann H, Neumann-Haefelin T: Early functional recovery and the fate of the diffusion/perfusion mismatch in patients with proximal middle cerebral artery occlusion. Cerebrovasc Dis 2004, 17:13-20.

54. Baird AE, Lovblad KO, Dashe JF, Connor A, Burzynski C, Schlaug G, Straroselskaya I, Edelman RR, Warach S: Clinical correlations of diffusion and perfusion lesion volumes in acute ischemic stroke. Cerebrovasc Dis 2000, 10:441-448.

55. Jansen O, Schellinger P, Fiebach J, Hacke W, Sartor K: Early recanalisation in acute ischaemic stroke saves tissue at risk defined by MRI. Lancet 1999, 353:2036-2037.

56. Hjort N, Butcher K, Davis SM, Kidwell CS, Koroshetz WJ, Rother J, Schellinger PD, Warach S, Ostergaard L: Magnetic resonance imaging criteria for thrombolysis in acute cerebral infarct. Stroke 2005, 36:388-397.

57. Baird TA, Parsons MW, Phanh T, Butcher KS, Desmond PM, Tress BM, Colman PG, Chambers BR, Davis SM: Persistent poststroke hyperglycemia is independently associated with infarct expansion and worse clinical outcome. Stroke 2003, 34:2208-2214.

58. Allport LE, Parsons MW, Butcher KS, MacGregor L, Desmond PM, Tress BM, Davis SM: Elevated hematocrit is associated with reduced reperfusion and tissue survival in acute stroke. Neurology 2005, 65:1382-1387.

59. Ay $\mathrm{H}$, Koroshetz WJ, Vangel M, Benner T, Melinosky C, Zhu M, Menezes N, Lopez CJ, Sorensen AG: Conversion of ischemic brain tissue into infarction increases with age. Stroke 2005, 36:2632-2636.

60. Singhal AB, Benner T, Roccatagliata L, Koroshetz WJ, Schaefer PW, Lo EH, Buonanno FS, Gonzalez RG, Sorensen AG: A pilot study of normobaric oxygen therapy in acute ischemic stroke. Stroke 2005, 36:797-802.

61. Thomalla GJ, Kucinski T, Schoder V, Fiehler J, Knab R, Zeumer H, Weiller C, Rother J: Prediction of malignant middle cerebral artery infarction by early perfusion- and diffusion-weighted magnetic resonance imaging. Stroke 2003, 34:1892-1899.

62. Oppenheim C, Samson $Y$, Manai R, Lalam T, Vandamme $X$, Crozier S, Srour A, Cornu P, Dormont D, Rancurel G, et al.: Prediction of malignant middle cerebral artery infarction by diffusion-weighted imaging. Stroke 2000, 31:2175-2181.

63. Kidwell CS, Saver JL, Mattiello J, Starkman S, Vinuela F, Duckwiler
G, Gobin YP, Jahan R, Vespa P, Villablanca JP, et al.: Diffusion-perfusion MRI characterization of post-recanalization hyperperfusion in humans. Neurology 2001, 57:2015-2021.

64. Rother J, de Crespigny AJ, D'Arceuil H, Iwai K, Moseley ME: Recovery of apparent diffusion coefficient after ischemiainduced spreading depression relates to cerebral perfusion gradient. Stroke 1996, 27:980-986; discussion 986-987.

65. Kidwell CS, Saver JL, Mattiello J, Starkman S, Vinuela F, Duckwiler G, Gobin YP, Jahan R, Vespa P, Kalafut M, et al:: Thrombolytic reversal of acute human cerebral ischemic injury shown by diffusion/perfusion magnetic resonance imaging. Ann Neurol 2000, 47:462-469.

66. Fiehler J, Knudsen K, Kucinski T, Kidwell CS, Alger JR, Thomalla G, Eckert B, Wittkugel O, Weiller C, Zeumer H, et al:: Predictors of apparent diffusion coefficient normalization in stroke patients. Stroke 2004, 35:514-519.

67. Guadagno JV, Warburton EA, Aigbirhio FI, Smielewski $\mathrm{P}$, Fryer TD, Harding S, Price CJ, Gillard JH, Carpenter TA, Baron JC: Does the acute diffusion-weighted imaging lesion represent penumbra as well as core? A combined quantitative PET/MRI voxel-based study. J Cereb Blood Flow Metab 2004, 24:12491254.

68. Guadagno JV, Warburton EA, Jones PS, Day DJ, Aigbirhio FI, Fryer TD, Harding S, Price CJ, Green HA, Barret O, et al: How affected is oxygen metabolism in DWI lesions?: a combined acute stroke PET-MR study. Neurology 2006, 67:824-829.

69. Rose SE, Janke AL, Griffin M, Finnigan S, Chalk JB: Improved prediction of final infarct volume using bolus delay-corrected perfusion-weighted MRI: implications for the ischemic penumbra. Stroke 2004, 35:2466-2471.

70. Sobesky J, Zaro Weber O, Lehnhardt FG, Hesselmann V, Neveling $M$, Jacobs $A$, Heiss WD: Does the mismatch match the penumbra? Magnetic resonance imaging and positron emission tomography in early ischemic stroke. Stroke 2005, 36: 980-985.

71. Khaja AM, Grotta JC: Established treatments for acute ischaemic stroke. Lancet 2007, 369:319-330.

72. Adams HP, Jr, del Zoppo G, Alberts MJ, Bhatt DL, Brass L, Furlan A, Grubb RL, Higashida RT, Jauch EC, Kidwell C, et al.: Guidelines for the early management of adults with ischemic stroke: a guideline from the American Heart Association/American Stroke Association Stroke Council, Clinical Cardiology Council, Cardiovascular Radiology and Intervention Council, and the Atherosclerotic Peripheral Vascular Disease and Quality of Care Outcomes in Research Interdisciplinary Working Groups: the American Academy of Neurology affirms the value of this guideline as an educational tool for neurologists. Stroke 2007, 38:1655-1711

73. Demchuk AM, Hill MD, Barber PA, Silver B, Patel SC, Levine SR: Importance of early ischemic computed tomography changes using ASPECTS in NINDS rtPA Stroke Study. Stroke 2005, 36: 2110-2115.

74. Fiehler J, Remmele C, Kucinski T, Rosenkranz M, Thomalla G, Weiller C, Zeumer H, Rother J: Reperfusion after severe local perfusion deficit precedes hemorrhagic transformation: an MRI study in acute stroke patients. Cerebrovasc Dis 2005, 19: 117-124.

75. Alsop DC, Makovetskaya E, Kumar S, Selim M, Schlaug G: Markedly reduced apparent blood volume on bolus contrast magnetic resonance imaging as a predictor of hemorrhage after thrombolytic therapy for acute ischemic stroke. Stroke 2005, 36:746-750.

76. Warach S, Latour LL: Evidence of reperfusion injury, exacerbated by thrombolytic therapy, in human focal brain ischemia using a novel imaging marker of early blood-brain barrier disruption. Stroke 2004, 35(11 Suppl 1):2659-2661

77. Thomalla G, Sobesky J, Kohrmann M, Fiebach JB, Fiehler J, Zaro Weber O, Kruetzelmann A, Kucinski T, Rosenkranz M, Rother J, et al.: Two tales: hemorrhagic transformation but not parenchymal hemorrhage after thrombolysis is related to severity and duration of ischemia: MRI study of acute stroke patients treated with intravenous tissue plasminogen activator within 6 hours. Stroke 2007, 38:313-318.

78. Kakuda W, Thijs VN, Lansberg MG, Bammer R, Wechsler L, Kemp S, Moseley ME, Marks MP, Albers GW: Clinical importance of microbleeds in patients receiving IV thrombolysis. Neurology 2005, 65:1175-1178. 
79. Kidwell CS, Saver JL, Villablanca JP, Duckwiler G, Fredieu A, Gough K, Leary MC, Starkman S, Gobin YP, Jahan R, et al:: Magnetic resonance imaging detection of microbleeds before thrombolysis: an emerging application. Stroke 2002, 33:95-98.

80. Chalela JA, Kidwell CS, Nentwich LM, Luby M, Butman JA, Demchuk AM, Hill MD, Patronas N, Latour L, Warach S: Magnetic resonance imaging and computed tomography in emergency assessment of patients with suspected acute stroke: a prospective comparison. Lancet 2007, 369:293-298.

81. Kang DW, Chalela JA, Dunn W, Warach S: MRI screening before standard tissue plasminogen activator therapy is feasible and safe. Stroke 2005, 36:1939-1943.

82. Schellinger PD, Jansen O, Fiebach JB, Pohlers O, Ryssel H, Heiland S, Steiner T, Hacke W, Sartor K: Feasibility and practicality of MR imaging of stroke in the management of hyperacute cerebral ischemia. Am J Neuroradiol 2000, 21:1184-1189.

83. Reeves MJ, Arora S, Broderick JP, Frankel M, Heinrich JP, Hickenbottom S, Karp H, LaBresh KA, Malarcher A, Mensah G, et al.: Acute stroke care in the US: results from 4 pilot prototypes of the Paul Coverdell National Acute Stroke Registry. Stroke 2005, 36:1232-1240.

84. Hacke W, Donnan G, Fieschi C, Kaste M, von Kummer R, Broderick JP, Brott T, Frankel M, Grotta JC, Haley EC, Jr, et al.: Association of outcome with early stroke treatment: pooled analysis of ATLANTIS, ECASS, and NINDS rt-PA stroke trials. Lancet 2004, 363:768-774.

85. Albers GW, Thijs VN, Wechsler L, Kemp S, Schlaug G, Skalabrin E, Bammer R, Kakuda W, Lansberg MG, Shuaib A, et al.: Magnetic resonance imaging profiles predict clinical response to early reperfusion: the diffusion and perfusion imaging evaluation for understanding stroke evolution (DEFUSE) study. Ann Neurol 2006, 60:508-517.

86. Butcher KS, Parsons M, MacGregor L, Barber PA, Chalk J, Bladin C, Levi C, Kimber T, Schultz D, Fink J, et al.: Refining the perfusion-diffusion mismatch hypothesis. Stroke 2005, 36:11531159.

87. Rother J, Schellinger PD, Gass A, Siebler M, Villringer A, Fiebach JB, Fiehler J, Jansen O, Kucinski T, Schoder V, et al.: Effect of intravenous thrombolysis on MRI parameters and functional outcome in acute stroke $<6$ hours. Stroke 2002, 33:24382445.

88. Ribo M, Molina CA, Rovira A, Quintana M, Delgado P, Montaner J, Grive E, Arenillas JF, Alvarez-Sabin J: Safety and efficacy of intravenous tissue plasminogen activator stroke treatment in the 3- to 6-hour window using multimodal transcranial Doppler/MRI selection protocol. Stroke 2005, 36:602-606.

89. Kohrmann M, Juttler E, Fiebach JB, Huttner HB, Siebert $S$, Schwark C, Ringleb PA, Schellinger PD, Hacke W: MRI versus CT-based thrombolysis treatment within and beyond the $3 \mathrm{~h}$ time window after stroke onset: a cohort study. Lancet Neurol 2006, 5:661-667.

90. Thomalla G, Schwark C, Sobesky J, Bluhmki E, Fiebach JB, Fiehler J, Zaro Weber O, Kucinski T, Juettler E, Ringleb PA, et al:: Outcome and symptomatic bleeding complications of intravenous thrombolysis within 6 hours in MRI-selected stroke patients: comparison of a German multicenter study with the pooled data of ATLANTIS, ECASS, and NINDS tPA trials. Stroke 2006, 37:852-858.

91. Schellinger P, Thomalla G, Kohrmann M: MRI-based thrombolysis is at least as safe and effective as standard CT-based treatment: a multicenter study of 1210 patients [abstract]. Stroke 2007, 38:454.

92. Hacke W, Albers G, Al-Rawi Y, Bogousslavsky J, Davalos A, Eliasziw M, Fischer M, Furlan A, Kaste M, Lees KR, et al.: The Desmoteplase in Acute Ischemic Stroke Trial (DIAS): a phase II MRI-based 9-hour window acute stroke thrombolysis trial with intravenous desmoteplase. Stroke 2005, 36:66-73.

93. Furlan AJ, Eyding D, Albers GW, Al-Rawi Y, Lees KR, Rowley HA, Sachara C, Soehngen M, Warach S, Hacke W: Dose Escalation of Desmoteplase for Acute Ischemic Stroke (DEDAS): evidence of safety and efficacy 3 to 9 hours after stroke onset. Stroke 2006, 37:1227-1231.

94. Ostrem JL, Saver JL, Alger JR, Starkman S, Leary MC, Duckwiler G, Jahan R, Vespa P, Villablanca JP, Gobin YP, et al:: Acute basilar artery occlusion: diffusion-perfusion MRI characterization of tissue salvage in patients receiving intra-arterial stroke therapies. Stroke 2004, 35:e30-e34.
95. Warach S, Pettigrew LC, Dashe JF, Pullicino P, Lefkowitz DM, Sabounjian L, Harnett K, Schwiderski U, Gammans R: Effect of citicoline on ischemic lesions as measured by diffusionweighted magnetic resonance imaging. Citicoline 010 Investigators. Ann Neurol 2000, 48:713-722.

96. Nakajima S, Meyer JS, Amano T, Shaw T, Okabe T, Mortel KF: Cerebral vasomotor responsiveness during $100 \%$ oxygen inhalation in cerebral ischemia. Arch Neurol 1983, 40:271-276.

97. Vahedi K, Hofmeijer J, Juettler E, Vicaut E, George B, Algra A, Amelink GJ, Schmiedeck P, Schwab S, Rothwell PM, et al.: Early decompressive surgery in malignant infarction of the middle cerebral artery: a pooled analysis of three randomised controlled trials. Lancet Neurol 2007, 6:215-222.

98. Jaramillo A, Gongora-Rivera F, Labreuche J, Hauw JJ, Amarenco P: Predictors for malignant middle cerebral artery infarctions: a postmortem analysis. Neurology 2006, 66:815-820.

99. Serena J, Blanco M, Castellanos M, Silva Y, Vivancos J, Moro MA, Leira R, Lizasoain I, Castillo J, Davalos A: The prediction of malignant cerebral infarction by molecular brain barrier disruption markers. Stroke 2005, 36:1921-1926.

100. Schwab S, Georgiadis D, Berrouschot J, Schellinger PD, Graffagnino C, Mayer SA: Feasibility and safety of moderate hypothermia after massive hemispheric infarction. Stroke 2001, 32:2033-2035.

101. Krieger DW, De Georgia MA, Abou-Chebl A, Andrefsky JC, Sila CA, Katzan IL, Mayberg MR, Furlan AJ: Cooling for acute ischemic brain damage (cool aid): an open pilot study of induced hypothermia in acute ischemic stroke. Stroke 2001, 32:1847-1854.

102. De Georgia MA, Krieger DW, Abou-Chebl A, Devlin TG, Jauss M, Davis SM, Koroshetz WJ, Rordorf G, Warach S: Cooling for Acute Ischemic Brain Damage (COOL AID): a feasibility trial of endovascular cooling. Neurology 2004, 63:312-317.

103. Berger C, Schramm P, Schwab S: Reduction of diffusionweighted MRI lesion volume after early moderate hypothermia in ischemic stroke. Stroke 2005, 36:e56-e58.

104. Ahmed N, Nasman P, Wahlgren NG: Effect of intravenous nimodipine on blood pressure and outcome after acute stroke. Stroke 2000, 31:1250-1255.

105. Geisler BS, Brandhoff F, Fiehler J, Saager C, Speck O, Rother J, Zeumer $H$, Kucinski T: Blood-oxygen-level-dependent MRI allows metabolic description of tissue at risk in acute stroke patients. Stroke 2006, 37:1778-1784

106. Sun PZ, Zhou J, Sun W, Huang J, van Zijl PC: Detection of the ischemic penumbra using $\mathrm{pH}$-weighted MRI. J Cereb Blood Flow Metab 2007, 27:1129-1136.

107. Baron JC: How healthy is the acutely reperfused ischemic penumbra? Cerebrovasc Dis 2005, 20(Suppl 2):25-31.

108. Saur D, Buchert R, Knab R, Weiller C, Rother J: lomazenilsingle-photon emission computed tomography reveals selective neuronal loss in magnetic resonance-defined mismatch areas. Stroke 2006, 37:2713-2719. 